\title{
The study of bloody fingerprint enhancement on paper with chemical reagents
}

\author{
Seung Lim ${ }^{\star}$, Im-Soon Kim, Jong-Yun Noh, Sang-Il Kim and Je-Sul Yu ${ }^{1}$ \\ Scientific Investigation Section, Gyungnam Provincial Police Agency, Changwon 641-797, Korea \\ ${ }^{I}$ Soonchunyang Univ. Graduate School of Forensic Science, Asan 336-745, Korea \\ (Received June 19, 2012; Revised August 28, 2012; Accepted August 28, 2012)
}

\section{화학시약들을 이용한 지류에서 혈흔지문 증강에 관한 연구 \\ 임 승ᄎ · 김임순 · 노종윤 · 김상일 · 유제설1 \\ 경남지방경찰청 과학수사계, ${ }^{1}$ 순천향대학교 법과학대학원 \\ (2012. 6. 19. 접수, 2012. 8. 28. 수정, 2012. 8. 28. 승인)}

\begin{abstract}
Bloody fingerprint is a very important evidence. In this study, we confirmed the enhancement effects of ninhydrin, leucocrystal violet (LCV), fuchsin acid, iodine and dimethylaminocinnamaldehyde (DMAC) on bloody fingerprints which were deposited on paper. Bloody fingerprint were deposited on paper sequentially and used after drying at room temperature. If a ridge of bloody fingerprint was clear, ninhydrin and LCV was the most effective but was not good for invisible ridge. Fuchsin acid reagent dyed paper surface so that the contrast of enhanced bloody fingerprint was decreased. Although bloody fingerprint was enhanced with iodine reagent, but the developed color was very weak after reaction. We thought that the enhancement effect of iodine to bloody fingerprint was negligible. Also, the enhancement effect of DMAC reagent to relatively clear bloody fingerprint was not good. However, it was very effective to faint or invisible ridge. By washing with methanol, contrast of enhanced bloody fingerprint was increased.
\end{abstract}

요 약: 혈흔지문은 매우 중요한 증거물이다. 본 실험은 지류에 유류된 혈흔지문에 대해 화학시약인 닌 히드린, leucocrystal violet (LCV), fuchsin acid, 요오드, dimethylaminocinnam aldehyde (DMAC) 시약들의 증강효과를 확인한 것이다. 혈흔지문은 종이에 순차적으로 유류시킨 후 실온에서 건조해 사용하였다. 혈 흔지문 융선이 비교적 선명할 경우에는 닌히드린과 LCV 시약이 가장 효과적이었지만, 눈에 보이지 않 는 융선에 대한 증강효과는 크지 않았다. Fuchsin acid 시약을 사용하면 종이 표면이 염색되므로 혈흔지 문의 contrast는 오히려 감소했다. 요오드 시약으로 혈흔지문 융선이 증강되긴 했지만, 반응 후 발색이 약 하고 증강효과도 크지 않았다. DMAC 시약은 선명한 혈흔지문에 대한 증강효과가 좋지 않았지만, 희미 한 융선에 대한 증강에는 매우 효과적이었다. 메탄올로 세척함으로서 DMAC로 증강된 혈흔지문의 contrast 를 높일 수 있었다.

Key words: bloody fingerprint, enhancement, paper, chemical reagents

Corresponding author

Phone : +82-(0)55-282-0182 Fax : +82-(0)55-284-3370

E-mail : lim-seung@hanmail.net 


\section{1. 서 론}

강력사건 현장에서 가해자의 손에 피해자의 혈액이 묻어 만들어진 혈흔지문이 자주 발견되는데, 피해자의 혈액으로 만들어진 혈흔지문은 매우 중요한 증거물이 다. 혈흔지문에서 가해자의 DNA 프로파일을 확보할 가능성이 낮다면, 혈흔지문을 증강해 지문을 유류한 사 람의 신원을 밝히는데 모든 노력을 기울여야만 한다. ${ }^{1}$

사람의 혈액은 적혈구, 백혈구, 혈소판과 혈장으로 구성되는데, 혈장은 혈액의 $55 \%$ 를 차지하며 성분의 $92 \%$ 가 수분이다. 그 외 단백질, 당, 무기물, 호르몬, 요 소, 요산, 지방과 같은 물질들이 존재한다. ${ }^{2}$ Langenburg 는 연구를 통해 사람의 손가락에서 혈액은 $3 \sim 4$ 분 이 내에 건조되며, 거의 마른 상태에서 지문융선이 보다 잘 유류된다는 사실을 밝혔다. 또한 손가락에 묻은 혈 액의 양, 기류, 주변온도, 혈액의 온도 및 피부의 온도 가 혈액의 건조 및 유류되는 지문융선의 상태에 영향 을 미치는 중요한 인자라는 것을 확인했다. ${ }^{3}$

혈흔지문을 증강할 때는 적혈구 내 존재하는 헤모 글로빈 또는 단백질과 반응하는 시약들이 주로 사용 되는데 혈액에는 단백질뿐만 아니라 단백질 분해물도 다량 존재한다. 헤모글로빈에 반응하는 혈흔 비 특이 적 반응시약으로서 3,3'-diaminobenzidine (DAB), 2,2'azino-di-[3-ethylbenzthiazolinesulfonate(6)] diammonium salts (ABTS), leucocrystal violet (LCV), leucomalachite green (LMG), ortho-tolidine, tetramethylbenzidine (TMB) 등이 있다. 단백질 염색시약으로서는 amido black, fuchsin acid, acid yellow 7, acid violet 17 등이 있는 데 혈흔지문 증강에는 염기성 염료보다는 산성 염료 가 효과적이라고 알려져 있다.,14-10 아미노산과 반응하 는 닌히드린과 1,8-Diazafluoren-9-one (DFO)는 주로 다공질 표면에 유류되어 있는 잠재지문을 현출할 때 사용하는 시약이지만 ${ }^{11-15} \mathrm{Sears}$ 등은 혈흔지문을 증강 할 때도 이 시약들이 매우 효과적으로 사용될 수 있 다는 사실을 확인했다. ${ }^{16}$

Theeuwen 등은 논문에서 비 다공질 표면에 유류된 혈흔문양을 증강할 때 $\mathrm{DFO}$, 닌히드린, $\mathrm{LCV}$, fuchsin acid와 amido balck 등의 사용을 권장했으며 ${ }^{4}$ Cullen 등도 비슷한 연구 결과를 발표했다. ${ }^{5}$ Amido black과 같은 단백질 염색시약을 사용하면 닌히드린이나 $\mathrm{DFO}$ 같은 방법을 재차 사용할 수 없으므로, 혈흔이 묻지 않은 곳에 존재하는 잠재지문은 더 이상 현출할 수 없게 된다. Allman과 Pounds는 범죄 현장에 존재하는 다공질 및 비 다공질 표면에 유류된 혈흔지문을 증강
할 때, 육안 검사를 한 후 요오드 시약을 사용하고 다 공질 표면이라면 닌히드린을 사용한 후 마지막으로 amido black이나 DAB를 사용하는 시약 처리절차를 제시했다. ${ }^{1}$

지문 분비물과 마찬가지로 혈액에도 지방과 요소 성분이 다량 포함되어 있지만, 혈액에 포함된 요소 함 량은 $293 \mathrm{mg} / \mathrm{L}$ 정도로 땀 성분에 포함된 양보다 3.6 배 낮다. ${ }^{17-19}$ 요오드는 잠재지문을 현출할 때 사용되는 가장 오래된 시약 중 하나로서 잠재지문 성분 중 피 지선에서 분비된 지방성분에 흡수되어 갈색의 지문을 현출한다. 다공질 및 비 다공질과 같은 다양한 표면 및 시약 적용이 까다로운 감열지 등에서 잠재지문을 현출할 때 주로 사용되고 있다. ${ }^{1,20}$ 혈흔지문 증강에는 사용되지 않지만 지문 분비물에 포함된 요소 성분과 반응해 잠재지문을 현출하는 시약으로서 dimethylaminocinnamaldehyde (DMAC)가 있다. DMAC 시약은 주로 다공질 표면에 유류된 잠재지문 현출에 사용되며, 현 출된 지문은 $450 \mathrm{~nm} 530 \mathrm{~nm}$ 범위의 파장에서 550 $\mathrm{nm}$ cut-off 필터를 이용해 관찰할 수 있다. 잠재지문을 현출할 때 $\mathrm{DMAC}$ 결정을 $150 \sim 200{ }^{\circ} \mathrm{C}$ 로 가열해 훈증 시키는 방법과 DMAC 용액에 담가 건조시킨 종이 사 이에 증거물을 넣고 강하게 압착하고 꺼내 일정시간 이 경과한 후 법광원으로 관찰하는 dry-transfer 방법 이 사용되고 있다. ${ }^{1,21-23}$

비 다공질 표면에 유류된 혈흔지문 증강과 관련된 연구에 비해 다공질 표면에 유류된 혈흔문양 증강에 대한 연구는 거의 찾아볼 수 없다. 잠재지문 현출시약 이나 비 다공질 표면에 유류된 혈흔지문 증강에 사용 되는 몇 가지 시약을 다공질 표면에서 혈흔지문을 증 강하는데 사용하고 있다. 이에 본 연구는 혈액 성분인 헤모글로빈, 단백질, 요소, 지방 성분과 반응해 지문을 현출 또는 증강시키는 시약들이 종이에 유류된 혈흔 지문에 미치는 영향을 확인하고, 종이에 유류된 혈흔 지문을 증강할 때 사용할 수 있는 적절한 시약 처리 절차를 제시하는데 있다.

\section{2. 실 험}

\section{1. 시약}

Fuchsin acid, leucocarystal violet, 4-dimethylaminocinnamaldehyde는 Acros (USA)에서, hydrogen peroxide (30\%), 2-propanol은 Junsei (Japan)에서, sulfosalicylic acid, acetic acid glacial, sodium acetate trihydrate, ninhydrin, methanol, petroleum ether는 Duksan (Korea) 
에서 구입하여 시약 제조에 사용하였다. 일회용 요오 드 호발기로 불리는 Fumette disposable lodine fuming gun은 Sirchie (USA)사에서 구입하였다.

\section{2. 장비}

닌히드린 시약으로 처리한 혈흔지문을 증강하기 위 해, 온·습도 조절이 가능한 Fingerprint verification chamber (Daeil Biotech, FCS-550, Korea)를 사용하였 으며, DMAC 시약으로 처리한 혈흔지문의 상태를 확 인하기 위해서 Spectrum 9000 (Omnichrome, USA)를 사용하였다. DMAC 시약을 처리한 혈흔지문의 형광 반응을 촬영하기 위해 deep yellow 필터 (Number 15, Tiffen, USA)를 적용했다. 혈흔지문 및 증강된 혈흔지 문을 촬영할 때 $60 \mathrm{~mm} \mathrm{AF} \mathrm{micro} \mathrm{렌즈를} \mathrm{장착한}$ Nikon D90 카메라 (Nikon, Japan)를 사용하였다.

\section{3. 혈흔지문의 유류}

실험에 사용된 모든 혈액은 한 사람의 것이며, 채혈 후 항응고제인 $\mathrm{K}_{2} \mathrm{EDTA}$ 가 함유된 $3.5 \mathrm{~mL}$ 짜리 $\mathrm{BD}$ Vacutainer에 담아 냉장보관하면서 사용하였다. 혈액 $30 \mu \mathrm{L}$ 를 손가락 끝에 떨어뜨린 후 손가락으로 문질러 지문융선 전체에 혈액이 묻게 한 후, 다공질인 종이 (A4)에 8차례 순차적으로 유류하였다. 혈흔지문이 유

Table 1. Enhancement chemicals and their preparations

\begin{tabular}{|c|c|}
\hline $\begin{array}{l}\text { Blood enhance- } \\
\text { ment reagent }\end{array}$ & Recipe \\
\hline Ninhydrin & $\begin{array}{l}\text { Staining : } 5 \mathrm{~g} \text { ninhydrin } \\
30 \mathrm{~mL} \text { methanol } \\
40 \mathrm{~mL} \text { 2-propanol } \\
930 \mathrm{~mL} \text { petroleum ether }\end{array}$ \\
\hline LCV & $\begin{array}{l}\text { Staining : } 2 \mathrm{~g} \text { leucocrystal violet } \\
20 \mathrm{~g} \text { sulfosalicylic acid } \\
7.4 \mathrm{~g} \text { sodium acetate } \\
100 \mathrm{~mL} \text { hydrogen peroxide }(30 \%) \\
900 \mathrm{~mL} \text { distilled water }\end{array}$ \\
\hline Fuchsin acid & $\begin{array}{l}\text { Staining }: 2 \mathrm{~g} \text { acid fuchsin } \\
1 \mathrm{~L} \text { distilled water } \\
\text { Washing : distilled water/acetic acid glacial } \\
(19: 1 \mathrm{v} / \mathrm{v})\end{array}$ \\
\hline Iodine & $\begin{array}{l}\text { Staining : disposable iodine fuming gun } \\
\text { (Sirchie) }\end{array}$ \\
\hline DMAC & $\begin{array}{l}\text { Staining : } 0.25 \mathrm{~g} \text { 4-diemthylaminocinnamalde- } \\
\text { hyde } \\
100 \mathrm{~mL} \text { methanol } \\
\text { Washing : methanol }\end{array}$ \\
\hline
\end{tabular}

류된 종이는 상온에서 1 시간 동안 건조시킨 후 실험 에 사용하였다.

\section{4. 시약의 제조 및 사용}

종이에 유류한 혈흔지문을 증강하는데 닌히드린, $\mathrm{LCV}$, fuchsin acid, 요오드, DMAC 시약을 사용하였다. 시약들의 제조법은 Table 1에 나타냈으며, 혈흔지문을 증강할 때 각각의 시약 처리법은 아래와 같다.

\subsection{1. 닌히드린 시약}

혈흔지문이 유류된 종이를 닌히드린 시약에 30 초 동안 담근 후 꺼내 상온에서 완전히 건조시켰다. 그 후, $70{ }^{\circ} \mathrm{C}$, 상대습도 $65 \%$ 조건으로 설정된 현출장비 에 넣고 30 분 동안 반응시킨 후 꺼냈고, 증강된 혈흔 지문을 사진 촬영하였다.

\subsubsection{LCV 시약}

제조한 LCV 시약을 분무기에 담아 혈흔지문이 유 류된 종이에 직접 분사하였다. 시약 처리된 종이를 상 온에서 건조시킨 후 증강된 혈흔지문을 사진 촬영하 였다. LCV 시약은 색을 띄지 않기 때문에 혈흔지문 을 증강한 후 종이를 세척하지 않았다.

\subsubsection{Fuchsin acid 시약}

제조한 시약을 사각용기에 담고 혈흔지문이 유류된 종이를 2분 동안 담근 후 꺼내, Table 1에 명시되어 있는 세척용액으로 세척하였다. 상온에서 종이를 건조 시킨 후 증강된 혈흔지문을 사진 촬영하였다.

\subsection{4. 요오드 시약}

본 실험에서 사용한 요오드 시약은 Sirchie 사에서 완제품 형태로 판매되는 일회용 제품으로서, 혈흔지문 이 유류된 종이에 직접 훈증하였다. 훈증한 후 증강된 혈흔지문을 즉시 사진 촬영하였다.

\subsubsection{DMAC 시약}

Dry-transfer 방법을 사용했으며 증강절차는 다음과 같다. 깨끗한 종이 (A4) 2장을 $0.25 \% \mathrm{DMAC}$ 시약에 1 분 동안 담근 후 꺼내 상온에서 완전히 건조시켰다. $\mathrm{DMAC}$ 시약이 묻어있는 두 장의 종이 사이에 혈흔지 문이 유류된 종이를 끼운 후 비닐봉지에 넣어 밀봉하 였다. 비닐봉지를 평평한 판으로 압착하고 24 시간 동 안 상온에서 보관하였다. 혈흔지문에서 관찰되는 형광 반응은 $470 ~ 530 \mathrm{~nm}$ 파장의 광원을 혈흔지문에 직접 
조사한 후 짙은 노랑색 필터를 장착한 사진기로 촬영 하였다. DMAC 시약을 사용한 후 배경에 묻은 시약 때문에 contrast가 떨어지는 혈흔지문은 메탄올로 세 척하였고, 동일한 방법으로 사진 촬영하였다.

\section{5. 순차적 시약 처리절차에 의한 혈흔지문 증강}

종이에 유류된 혈흔지문이 육안으로 선명하지 않고 혈흔지문 융선의 일부가 관찰되면, 혈액 이외에 잠재 지문 성분이 유류되어 있을 가능성이 높기 때문에, 혈 흔지문 증강에 사용할 수 있는 시약들의 반응특성들 을 고려한 후 사용 순서를 결정했다. 대부분의 논문에 서 아미노산 반응시약을 먼저 사용한 후 헤모글로빈 반응 또는 단백질 염색 시약을 사용하도록 권장하고 있다. ${ }^{1}$ 적절한 시약 처리절차를 확인하기 위해, 종이에
순차적으로 유류된 혈흔지문을 닌히드린 시약으로 처 리해 증강시킨 후, LCV 또는 fuchsin acid 시약으로 다시 처리하는 절차와, $\mathrm{DMAC}$ 시약으로 혈흔지문을 증강한 후 닌히드린 또는 $\mathrm{LCV}$ 로 처리하는 절차에 의 해 얻어진 결과를 비교하였다. 시약들의 사용법은 2.4 에서 제시한 것과 동일하다.

\section{3. 결과 및 고찰}

\section{1. 시약 종류가 혈흔지문 증강에 미치는 영향}

혈액의 구성성분들을 고려해, 헤모글로빈, 단백질, 아미노산, 지방, 요소와 반응할 수 있는 5가지 종류의 시약을 선택했고 종이에 유류된 혈흔지문을 증강할 때 사용했다. 각각의 시약들을 처리한 후 증강된 혈흔

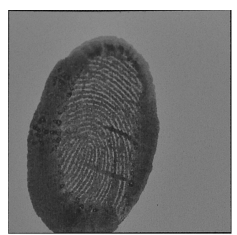

(a)

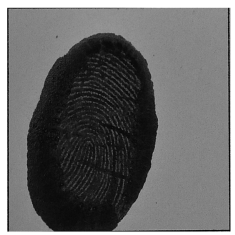

(f)

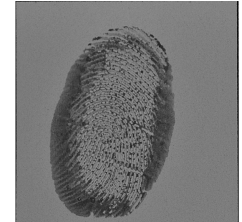

(b)

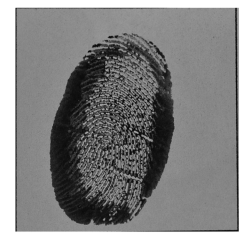

(g)

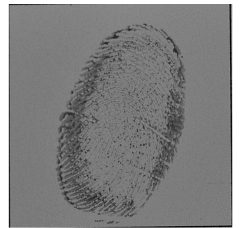

(c)

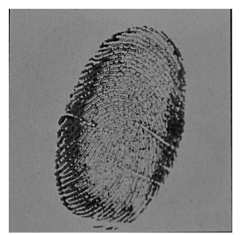

(h)

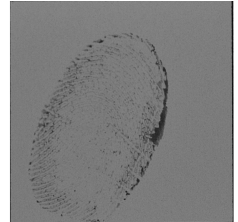

(d)

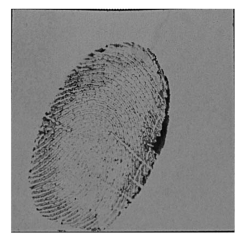

(i)

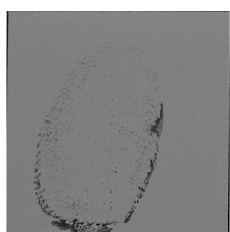

(e)

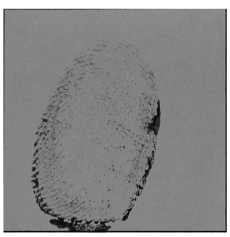

(j)

Fig. 1. Diminishing series of bloody fingerprints on paper (A4) and after enhancement with ninhydrin reagent. (a) (e) are $1^{\text {st }} \sim 5^{\text {th }}$ diminishing series, (f) (j) are enhanced bloody fingerprints.

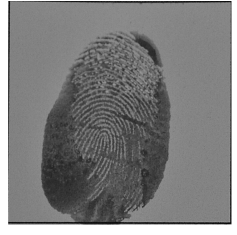

(a)

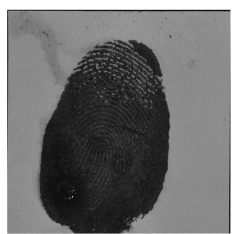

(f)

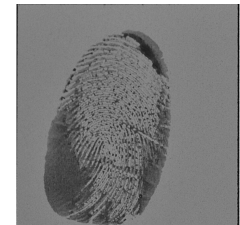

(b)

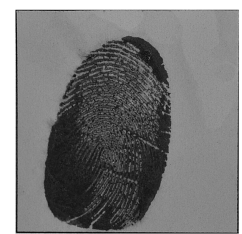

(g)

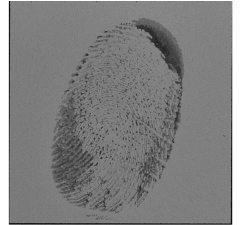

(c)

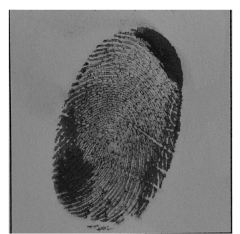

(h)

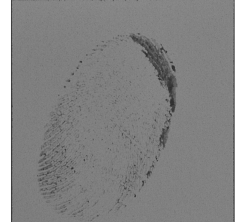

(d)

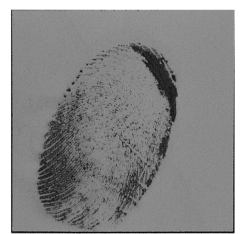

(i)

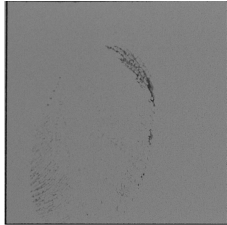

(e)

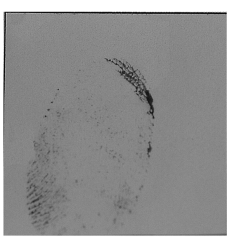

(j)

Fig. 2. Diminishing series of bloody fingerprints on paper (A4) and after enhancement with LCV regent. (a) (e) are $1^{\text {st }} 5^{\text {th }}$ diminishing series, (f) $\sim(j)$ are enhanced bloody fingerprints. 


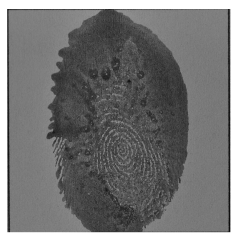

(a)

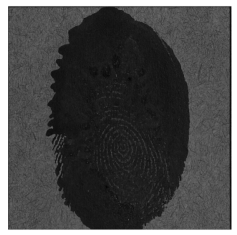

(f)

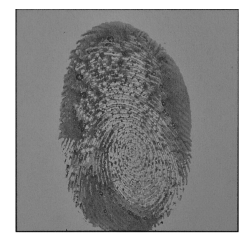

(b)

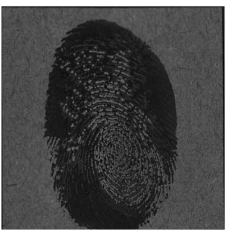

(g)

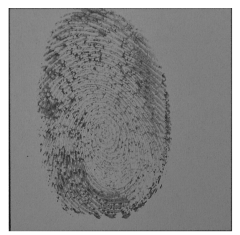

(c)

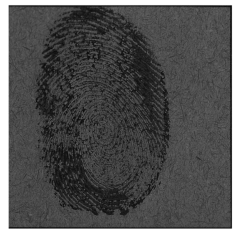

(h)

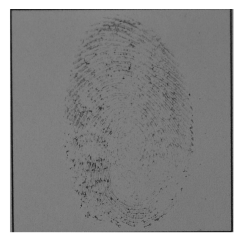

(d)

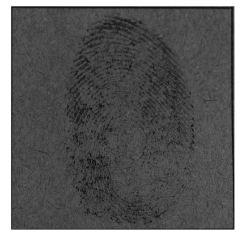

(i)

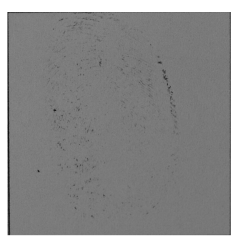

(e)

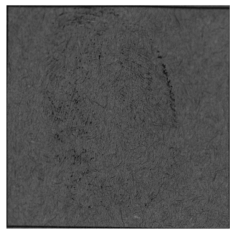

(j)

Fig. 3. Diminishing series of bloody fingerprints on paper (A4) and after enhancement with fuchsin acid reagent. (a) (e) are $1^{\text {st }} \sim 5^{\text {th }}$ diminishing series, (f) (j) are enhanced bloody fingerprints.

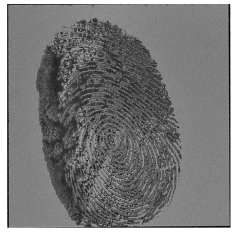

(a)

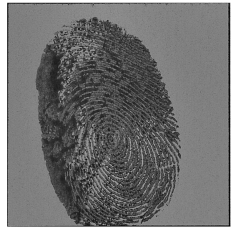

(f)

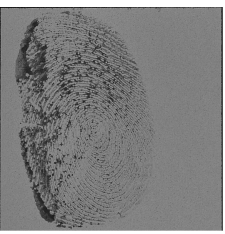

(b)

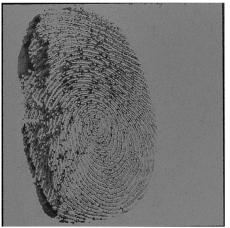

(g)

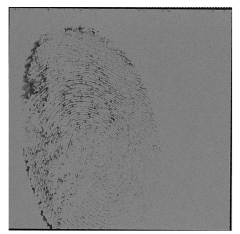

(c)

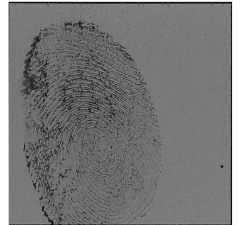

(h)

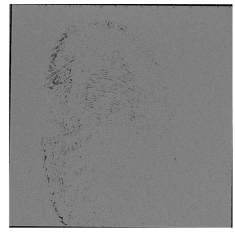

(d)

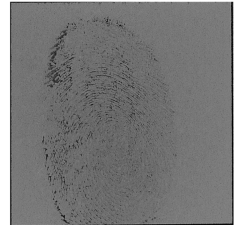

(i)

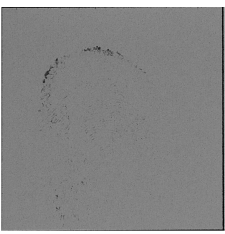

(e)

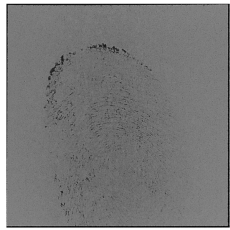

(j)

Fig. 4. Diminishing series of bloody fingerprints on paper (A4) and after enhancement with disposal iodine fuming gun. (a) (e) are $1^{\text {st }} \sim 5^{\text {th }}$ diminishing series, (f) $\sim(\mathrm{j})$ are enhanced bloody fingerprints.

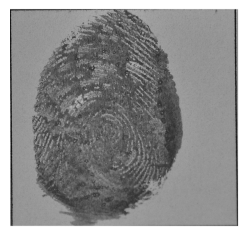

(a)

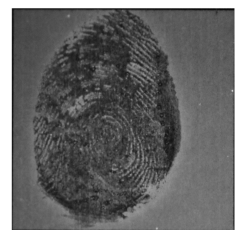

(f)

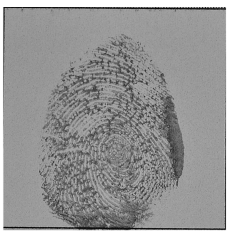

(b)

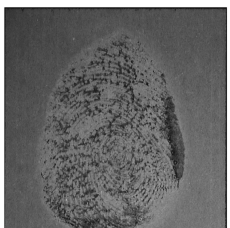

(g)

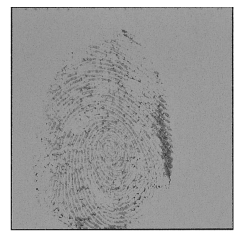

(c)

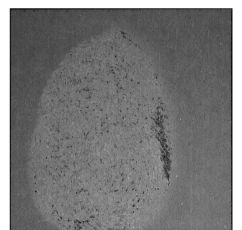

(h)

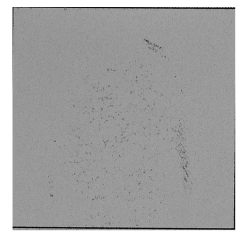

(d)

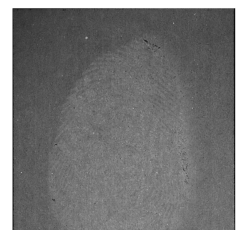

(i)

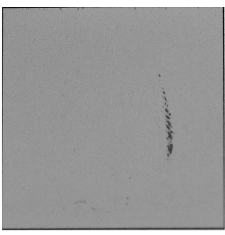

(e)

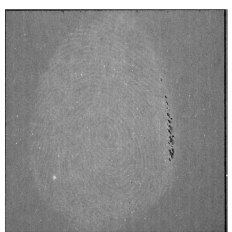

(j)

Fig. 5. Diminishing series of bloody fingerprints on paper (A4) and after enhancement with DMAC reagent. (a) $\sim(\mathrm{e})$ are $1^{\text {st }} \sim 5^{\text {th }}$ diminishing series, (f) (j) are enhanced bloody fingerprints. 
지문은 Fig. 1 5에서 볼 수 있다. 손가락 끝에 혈액을 떨어뜨린 후, 종이에 혈흔지문을 8차례에 걸쳐 순차적 으로 유류했지만 4 5차례 이상 연속적으로 유류했을 때부터는 육안으로 혈흔지문의 융선이 거의 식별되지 않았다. 6차례 이상 유류했을 때부터는 혈흔지문인지 잠재지문 인지를 구분할 수 없었기 때문에, 본 실험에 서는 결과를 언급하지 않았다.

Fig. 1은 종이에 유류된 혈흔지문을 닌히드린 시약 으로 증강한 결과를 보여준다. 혈액이 다량 묻어 있거 나 육안으로 혈액이 묻어 있는 것이 확인된 지문융선 은 효과적으로 증강되었지만, 혈액이 확인되지 않는 지문융선은 거의 증강되지 않았다. 이런 사실은 혈흔 지문인 (e)와 닌히드린 시약을 사용한 후 증강된 혈흔 지문 (j)를 통해서 보다 분명히 알 수 있다. Fig. 2는 $\mathrm{LCV}$ 시약 사용 후 증강된 혈흔지문의 상태를 보여주 는데, 닌히드린 시약 처리에 따른 혈흔지문 증강 결과 와 비슷하다. $\mathrm{LCV}$ 시약은 혈액성분 중 헤모글로빈에 만 민감하게 반응하므로, 고도로 희석된 혈액과도 발 색반응이 일어난다. ${ }^{4} \mathrm{LCV}$ 시약을 사용한 후 혈흔지문 융선이 증강되지 않은 지역은 종이에 순차적인 혈흔 지문을 유류할 때 헤모글로빈이 거의 묻지 않는 지역 으로 생각된다.

Fig. 3은 fuchsin acid 시약 처리를 통해 증강된 혈흔지문의 상태를 보여준다. 다른 시약들과 달리 fuchsin acid는 시약 자체가 붉은색을 띄므로, 혈흔 지문을 증강한 후 증강된 혈흔지문의 contrast를 높 이기 위해서 세척해야 한다. 종이에 유류된 혈흔지 문 증강에 fuchsin acid 시약을 사용하면 혈흔지문 융선 상태는 개선되지 않았고, 희미한 혈흔지문 융 선의 상태는 오히려 더 나빠질 가능성이 있음을 Fig. 3의 (d)와 (e), 증강 후 촬영한 (i), (j)를 통해 알 수 있다. 이런 결과는 세척 중에 융선에 존재하 던 혈흔의 일부가 씻겨 나갔기 때문에 발생한 결과 이거나, 종이와 같은 다공질 표면에 색을 띄는 염료 를 사용하면 세척 후에도 표면에 착색된 시약이 효 과적으로 제거되지 않아 혈흔지문의 contrast가 떨어 지기 때문이라고 생각된다.

Fig. 4는 1회용 요오드 호발기를 사용해 증강된 혈 흔지문의 상태를 보여준다. 닌히드린, $\mathrm{LCV}$, fuchsin acid 시약 처리 결과와는 달리, 시약 처리 후에 혈흔지 문 중 융선이 전혀 보이지 않는 지역에서 지문융선의 일부가 관찰되었다. 혈흔지문에 존재하는 지방성분들 이 요오드 시약과 반응해 만들어진 결과로 판단되지 만, 지문융선에서 개인식별을 할 때 필요한 특징점들
은 관찰되지 않았다. 눈에 보이지 않던 일부 혈흔지문 융선들이 관찰되긴 했지만, Fig. 4의 (b)와 같이 육안 으로 선명한 혈흔지문이라도 시약처리 후 contrast가 크게 개선되지 않았기 때문에 요오드 시약이 혈흔지 문 증강에 효과적이라고 판단할 수 없었다.

DMAC 시약을 사용했을 때의 혈흔지문 상태는 Fig. 5 를 통해 알 수 있다. DMAC 시약은 반응 후에 도 발색되지 않았기 때문에, 법광원을 사용하지 않고 는 증강효과를 확인할 수 없었다. 그림에서 보듯이, 혈흔지문이 육안으로 선명하면 유류된 혈흔지문 전체 에서 형광반응이 일어나 증강된 혈흔지문 융선의 관 찰이 어려웠지만, 혈흔지문 융선이 희미할 경우에는 비교적 선명한 혈흔지문 융선이 관찰되었다. 요소는 수용성 물질로서 혈장에 존재하는데, 혈장의 수분 함 량이 $92 \%$ 정도 되므로 다공질인 종이 표면에서 빠르 게 확산되었기 때문에 발생한 결과라고 추정된다. 이 런 결과를 토대로, DMAC 시약은 혈흔 지문의 융선 이 매우 희미할 경우 선택적으로 사용할 수 있는 시 약이라고 판단하였다.

혈흔지문을 DMAC 시약으로 처리하면, 지문 이외 의 종이 표면이 노랗게 염색되는데, Fig. 5 의 결과처 럼 증강된 혈흔지문의 contrast가 문제될 수 있다. 증 강된 혈흔지문을 메탄올로 세척해 이런 문제를 해결 할 수 있었고, Fig. 6에 나타냈다. Fig. 6의 (a) (c)는 Fig. 5의 (h) (j)를 메탄올로 세척한 후 $500 \mathrm{~nm}$ 파장의 광원 하에서 짙은 노란색 필터를 이용해 촬영한 사진 이다. 혈흔과 DMAC와 요소가 반응한 후 만들어진 반응산물은 메탄올에서 용해되지 않기 때문에, 메탄올 로 세척한 후에는 혈흔지문의 contrast가 크게 개선되 었고, 보이지 않던 융선과 융선에 존재하는 특징점들 이 선명하게 관찰되었다.

\section{2. 순차적 시약 처리절차에 의한 혈흔지문 증강}

한 종류의 시약을 사용해 종이에 유류된 혈흔지문 을 증강할 때는 닌히드린, $\mathrm{LCV}, \mathrm{DMAC}$ 시약이 효과

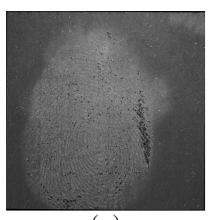

(a)

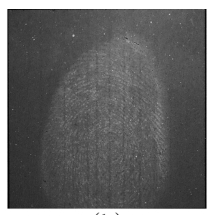

(b)

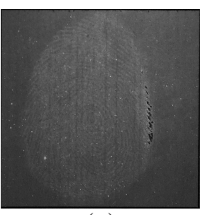

(c)
Fig. 6. Methanol washing of DMAC enhanced bloody fingerprints. (a) $3^{\text {rd }}$ diminishing series, (b) $4^{\text {th }}$ diminishing series, (c) $5^{\text {th }}$ diminishing series in fig. 5 . 


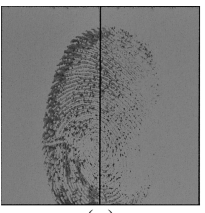

(a)

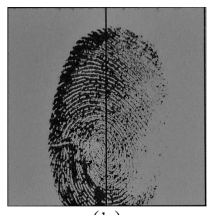

(b)

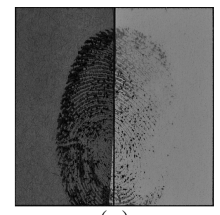

(c)
Fig. 7. The sequence of method for the enhancement of bloody fingerprint on paper (a) bloody fingerprint, (b) enhancement with ninhydrin reagent, (c) enhancement with fuchsin acid/leucocrystal violet reagent after using the ninhydrin reagent.

적이란 사실을 실험을 통해 확인했다. 문헌에 의하 면 혈흔지문에는 혈흔이 묻어 있지 않는 부분이 있 을 수 있기 때문에, 증강 시에는 아미노산 반응시약 인 $\mathrm{DFO}$ 나 닌히드린을 먼저 사용한 후에 단백질 염 색시약이나 헤모글로빈 반응시약으로 처리할 것을 권장하고 있다. ${ }^{1}$ 종이에 유류된 혈흔지문 증강 시에 적절한 시약 처리절차를 확인하기 위해, 닌히드린 시약으로 증강된 혈흔지문을 fuchsin acid와 LCV 시 약으로 다시 처리한 후 지문의 상태를 확인했다(Fig. 7). 이와 별도로, DMAC 시약으로 혈흔지문을 증강 한 후에 닌히드린과 $\mathrm{LCV}$ 시약을 사용해 다시 증강 시켰을 때의 결과는 Fig. 8에 나타냈다. Fig. 7에서 보듯이, 닌히드린 시약으로 증강된 혈흔지문에 fuchsin acid 시약을 처리하면 종이 표면에 착색이 일어나 혈흔지문의 contrast와 융선의 선명도가 다소 떨어졌다. 증강된 혈흔지문에 $\mathrm{LCV}$ 시약을 처리할 경우에도 혈흔지문의 융선 선명도는 매우 감소하였 다. 순차적 시약 처리절차에 의해 혈흔지문을 증강 할 때 닌히드린 시약을 먼저 사용한 후 다른 시약으 로 재처리하는 방법은 적절치 않다고 생각된다. $\mathrm{DMAC}$ 는 잠재지문 현출에도 효과적인 시약이므로, ${ }^{21-23}$ 혈흔지문을 증강할 때도 닌히드린 시약과 동일한 목적 으로 사용할 수 있다. Fig. 8에서 보듯이, DMAC 시 약으로 증강한 혈흔지문에서는 융선에 존재하는 특 징점들이 비교적 잘 관찰되었으며, 닌히드린 또는 $\mathrm{LCV}$ 시약을 추가적으로 처리했을 때조차 강하게 발 색되므로 별다른 문제가 없었다. DMAC 시약을 사 용한 후에 닌히드린 또는 $\mathrm{LCV}$ 시약 처리가 가능한 것은, 반응하는 성분이 다르고 $\mathrm{DMAC}$ 시약으로 증 강하는 과정에서 종이에 유류된 혈흔지문이 훼손되 지 않았기 때문일 것으로 생각된다. 본 실험 결과를 통해, 종이에 유류된 혈흔지문 증강 시에는 DMAC 시약을 가장 먼저 사용하는 것이 효과적임을 알 수 있었다.

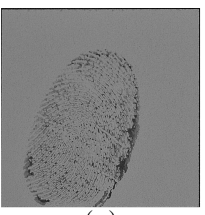

(a)

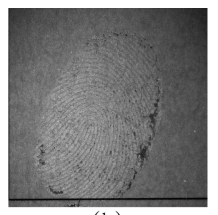

(b)

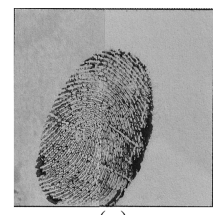

(c)
Fig. 8. The sequence of method for the enhancement of bloody fingerprint on paper (a) bloody fingerprint, (b) enhancement with DMAC reagent, (c) enhancement with ninhydrin/leucocrystal violet reagent after using the DMAC reagent.

\section{4. 결 론}

본 연구는 혈액 중에 포함된 헤모글로빈, 단백질, 아미노산, 지방, 요소 성분과 반응하는 시약 5 가지를 선택한 후, 각각의 시약들이 종이에 유류된 혈흔지문 증강에 미치는 영향을 확인한 것이다. 또한 실험 결 과를 바탕으로 지류에 유류된 혈흔지문을 증강할 때 사용할 수 있는 적절한 시약 처리절차를 제시하는데 있다.

종이에 순차적으로 유류한 혈흔지문은 유류 횟수가 증가할수록 융선의 일부만 관찰되므로 혈흔지문인지 잠재지문인지 조차도 구분하기 어려워졌다. 혈흔지문 융선이 선명한 경우에는 시약처리 없이도 특징점이 확인되었지만, 선명하더라도 혈액이 다량 묻어 융선이 확인되지 않는 경우에는 시약 처리에 의해 개선할 수 없었다.

혈흔지문을 증강할 때 닌히드린 및 $\mathrm{LCV}$ 시약을 사 용하면 선명하지 않더라도 눈에 보이는 융선은 증강 되지만 눈에 보이지 않는 융선은 거의 증강되지 않았 다. Fuchsin acid 시약을 사용할 경우에는, 종이 표면 이 시약으로 염색되어 희미한 융선의 contrast는 오히 려 떨어졌다. 단백질 염색 시약은 종이와 같은 다공질 표면에 유류된 혈흔지문 증강에 적절하지 않다고 판 단하였다. 요오드 시약은 혈액과 반응한 후 발색되지 만, 발색되는 정도가 약해 혈흔지문 증강에는 한계가 있었다. DMAC 시약으로 증강된 혈흔지문은 발색되 지 않으므로, 육안으로는 증강 효과를 확인할 수 없었 다. DMAC 시약은 상태가 좋은 혈흔지문에 대해 증 강효과가 없었지만 희미하거나 눈에 보이지 않는 융 선의 증강에는 매우 효과적이었다. DMAC 시약을 사 용한 후 혈흔지문 이외의 표면이 염색되어 증강된 지 문의 contrast가 떨어지는 현상은 메탄올로 세척해 개 선시킬 수 있었다. 혈흔지문 증강 시약은 혈흔지문 융 선이 흐릿하거나 융선이 진행하는 도중에 끊겼을 때 
사용해야 하며, 혈흔지문의 상태가 좋다면 닌히드린이 나 $\mathrm{LCV}$ 시약을, 혈흔지문의 상태가 나쁘다면 DMAC 를 사용하는 것이 가장 효과적이란 사실을 알 수 있 었다.

혈흔지문을 증강할 때는 다양한 종류의 시약들을 순차적으로 처리하는 방법이 권장되는데, 닌히드린 시 약을 사용한 후 LCV나 fuchsin acid로 다시 증강하는 방법은 증강된 혈흔지문의 상태를 오히려 떨어뜨리므 로 효과적이지 않을 수 있다. DMAC 시약을 가장 먼 저 사용하면, 종이에 유류된 혈흔지문이 훼손되지 않 을 뿐만 아니라, 증강된 지문에 닌히드린이나 LCV와 같은 시약을 다시 사용할 때 발색에 문제를 일으키지 않았다. 종이에 유류된 혈흔지문을 증강할 때는 혈흔 지문의 상태를 육안 또는 $425 \mathrm{~nm}$ 파장의 광원으로 관찰한 후, 증강이 필요하다면 $\mathrm{DMAC}$ 시약을 가장 먼저 사용해야하며 닌히드린 또는 $\mathrm{LCV}$ 시약은 이차 적으로 사용하는 것이 적절하다고 판단하였다.

\section{참고문헌}

1. C. Champod, C. Lennard, P. Margot and M. Stoilovic, 'Fingerprints and Other Ridge Skin Impressions', CRC press: Boca Raton, Florida, 2004.

2. http://en.wikipedia.org/wiki/Blood.

3. G. Langenburg, J. Forensic Ident., 58(3), 355-389 (2008).

4. A. B. E. Theeuwen, S. van Barneveld, J. W. Drok, I. Keereweer, J. C. M. Limborgh, W. M. Naber and T. Velders, Forensic Sci. Int., 95, 133-151 (1998).

5. S. Cullen, A. Otto and P. N. Cheetham, J. Forensic Ident., 60(1), 45-60 (2010).

6. A. L. Michaud, L. B. Conti, J. Forensic Sci., 49(3), 1-6 (2004).

7. J. P. Caldwell, W. Henderson and N. D. Kim, J. Forensic Sci., 45(4), 785-794 (2000).
8. E. H. Holder, L. O. Robinson and J. H. Laub, 'The fingerprint sourcebook' National Institute of Justice, Washington DC, 2011.

9. V. Sears and T. M. Prizeman, J. Forensic Ident., 50(5), 470-480 (2000).

10. V. Sears, C. Butcher and T. M. Prizeman, J. Forensic Ident., 51(1), 28-38 (2001).

11. C. L. Lennard, P. A. Margot, M. Sterns and R. N. Warrener, J. Forensic Sci., 32(3), 597-605 (1987).

12. J. Almog, A. Hirshfeld and J. T. Klug, J. Forensic Sci., 27(4), 912-917 (1982).

13. O. P. Jasuja, M. A. Toofany, G. Singh and G. S. Sodhi, Sci. Justice, 49, 8-11 (2009).

14. R. Jelly, E. L. T. Patton, C. Lennard, S. W. Lewis and K. F. Lim, Anal. Chim. Acta, 652, 128-142 (2009).

15. S. C. Roh, M. J. Choi, M. K. Kim, O. T. Lee and S. W. Park, Anal. Sci. Technol., 20(2), 155-163 (2007).

16. V. Sears, C. Butcher and L. A. Fitzgerald, J. Forensic Ident., 55(6), 741-763 (2005).

17. B. S. Kim, J. H. Kang, K. S. Kim, S. J. Lee, M. H. Lee and J. R. Park, Korean Circ. J., 28(7) 1122-1130 (1998).

18. C. T. Huang, M. L. Chen and I. F. Mao, Chinese J. Physiol., 45(3), 109-115 (2002).

19. E. M. Mackay and L. L. Mackay, J. Clin. Invest., 4(2), 295-306 (1927).

20. O. M. Jasuja and G. Singh, Forensic Sci. Int., 192, 1116 (2009).

21. J. Brennan, S. Bramble, S. Crabtree and G. Wright, J. Forensic Ident., 45(4), 373-380 (1995).

22. Y. Sasson and J. Almog, J. Forensic Sci., 23(4), 1-6 (1978).

23. I. Hussain and U. Shaukat, J. Chem. Soc. Pak., 24(4), 282-290 (2002). 